\section{OP0226 SOLID TUMOUR OUTCOMES IN PATIENTS WITH RA TREATED WITH ABATACEPT AND OTHER DMARDS: RESULTS FROM A 10-YEAR INTERNATIONAL POST- APPROVAL STUDY}

Teresa Simon ${ }^{1}$, Samy Suissa ${ }^{2}$, Mary Lou Skovron ${ }^{1}$, Thomas Frisell ${ }^{3}$, Johan Askling ${ }^{3}$, Kaleb Michaud $^{4,5}$, Sofia Pedro ${ }^{5}$, Anja Strangfeld ${ }^{6}$, Maarten Boers ${ }^{7}$, Diane Lacaille ${ }^{8}$, Marc Hochberg ${ }^{9}$, Andres Gomez ${ }^{1}{ }^{1}$ Bristol-Myers Squibb, Princeton, United States of America; ${ }^{2}$ Mc Gill University, Montreal, Canada ${ }^{3}$ Karolinska Institutet, Stockholm, Sweden; ${ }^{4}$ University of Nebraska Medical Center, Omaha, United States of America; ${ }^{5}$ FORWARD, The National Databank for Rheumatic Diseases, Wichita, United States of America; ${ }^{6}$ German Rheumatism Research Centre, Berlin, Germany; ${ }^{7}$ VU University Medical Center, Amsterdam, Netherlands; ${ }^{8}$ Arthritis Research Center, Richmond, Canada; ${ }^{9}$ University of Maryland, Baltimore, United States of America

Background: The abatacept global post-marketing epidemiology programme includes observational studies based on biologic disease registries and healthcare claims database studies to evaluate infection and malignancy risks associated with abatacept treatment, as used in routine clinical practice.

Objectives: To assess the risk of solid tumour malignancies in patients with RA treated with abatacept vs conventional synthetic (cs)DMARDs and other biologic (b) or targeted synthetic (ts)DMARDs.

Methods: Data were analysed from four cohorts: two biologic registries (the AntiRheumatic Therapy in Sweden [ARTIS] register and the Rheumatoid Arthritis Observation of Biologic Therapy [RABBIT] German registry), a disease registry (FORWARD, The National Databank for Rheumatic Diseases in the USA) and a healthcare claims database (the population-based British Columbia Canadian RA Cohort [BC]). Exposure defined as "ever exposed" unless specified. Crude incidence rates (per 1000 patient-years of exposure) with $95 \%$ Cls were calculated for overall malignancy, breast cancer, lung cancer and lymphoma. Adjusted risk ratios (RRs) with $95 \% \mathrm{Cls}$ were estimated using multivariate models adjusting for demographics, comorbidities and other potential cofounders within each database and were subsequently pooled using a random-effects model for metaanalyses. ${ }^{1}$

Results: Patients treated with abatacept ( 5100$)$, csDMARDs ( 74K) and other b/tsDMARDs ( 37K) were followed up for a mean of 3.0-3.7, 3.0-6.2 and 3.0-4.7 years, respectively. Patients were mainly female $(71-86 \%)$, with a mean age ranging from $55-63$ years, and $4-34 \%$ had a history of malignancy. A greater number of abatacept-treated patients had been treated with $\geq 2$ prior biologics (abatacept, 44-85\%; csDMARDs, 11\% [FORWARD] and other b/tsDMARDs, 0$19 \%)$. The incidence rate of overall malignancy in abatacept-treated patients was low (Table). Adjusted RRs $(95 \% \mathrm{Cls})$ for abatacept vs csDMARDs (range: 0.8 $[0.2,3.4]$ to $1.3[0.5,3.3]$; pooled estimate: $1.1[0.8,1.5]$ ) and abatacept vs other b/ tsDMARDs (range: $1.0[0.4,2.6]$ to $1.2[0.6,2.3]$; pooled estimate: $1.0[0.8,1.3]$ ) showed no increased risk in overall malignancy. Although individual registries showed a slight increase in breast (BC), lung (RABBIT) and lymphoma (ARTIS) cancers in patients treated with abatacept, numbers were too low to make an accurate comparative risk assessment.

Conclusion: While the development of malignancy is a potential risk associated with the use of immunomodulators, data from this large, international, post-marketing epidemiology programme suggest that the risks of overall malignancy and breast, lung or lymphoma cancers were not significantly increased in patients treated with abatacept. These data are consistent with the established safety profile of abatacept.

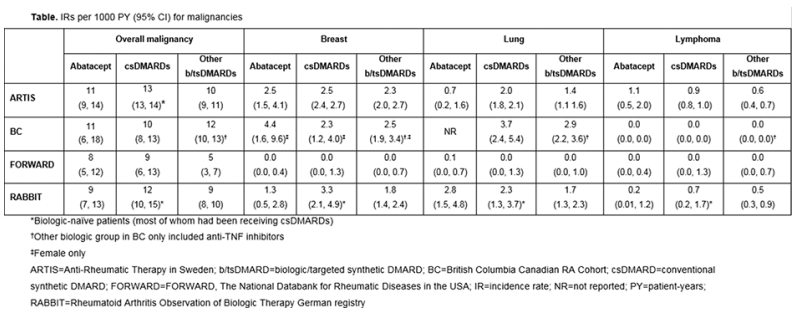

REFERENCE:

[1] DerSimonian R, Laird N. Control Clin Trials 1986;7:177-88.

Acknowledgement: Professional Medical writing: Claire Line, PhD, Caudex; funding: Bristol-Myers Squibb

Disclosure of Interests: Teresa Simon Employee of: Bristol-Myers Squibb, Samy Suissa Grant/research support from: Advisory board meetings, or as speaker, or received research grants from AstraZeneca, Bayer, Boehringer-Ingelheim, Bristol-Myers Squibb, Novartis, Speakers bureau: Advisory board meetings, or as speaker, or received research grants from AstraZeneca, Bayer, Boehringer-Ingelheim, Bristol-Myers Squibb, Novartis, Mary Lou Skovron
Shareholder of: Bristol-Myers Squibb, Consultant for: Bristol-Myers Squibb, Thomas Frisell: None declared, Johan Askling Grant/research support from: Karolinska Institutet (JA) has or has had research agreements with the following pharmaceutical companies, mainly in the context of the ATRIS national safety monitoring programme for rheumatology biologicals: Abbvie, BMS, MSD, Eli Lilly, Pfizer, Roche, Samsung Bioepis, and UCB., Consultant for: Karolinska Institutet has received remuneration for JA participating in ad boards arranged by Lilly, Novartis, and Pfizer., Kaleb Michaud Grant/research support from: Research grant funding in the last 2 years from Rheumatology Research Foundation and Pfizer, Sofia Pedro Employee of: FORWARD, The National Data Bank of Rheumatic Diseases, Anja Strangfeld Speakers bureau: Speakers fees from BristolMyers Squibb, MSD, Pfizer, Roche, Maarten Boers Consultant for: Bristol-Myers Squibb, Teva, Novartis, Pfizer, GlaxoSmithKline, Diane Lacaille Grant/research support from: Bristol-Myers Squibb and Eli Lilly Canada, Marc Hochberg Shareholder of: BriOri Biotech, Theralogix LLC., Consultant for: Bristol Myers Squibb, Eli Lilly, EMD Serono, Novartis Pharma AG, Pfizer Inc., Samumed LLC, Symic Bio Inc., Theralogix LLC, TissueGene Inc., TLC Biopharmaceuticals, Inc. Zynerba, Galapagos, IQVIA, Hoffman LaRoche., Andres Gomez Shareholder of: Bristol-Myers Squibb, Employee of: Bristol-Myers Squibb DOI: 10.1136/annrheumdis-2019-eular.1663

\section{OP0227 \\ EFFECTS OF SUCCESSIVE SWITCHES TO DIFFERENT BIOSIMILARS INFLIXIMAB ON IMMUNOGENICITY IN CHRONIC INFLAMMATORY DISEASES IN DAILY CLINICAL PRACTICE}

Ambre Lauret ${ }^{1}$, Anna Moltó ${ }^{1}$, Vered Abitbol ${ }^{2}$, Loriane Gutermann ${ }^{3}$, Ornella Conort ${ }^{3}$ Francois Chast ${ }^{3}$, Claire Goulvestre ${ }^{4}$, Claire Le Jeunne ${ }^{5}$, Stanislas Chaussade ${ }^{2}$, Christian Roux ${ }^{1}$, Frédéric Batteux ${ }^{4}$, Maxime Dougados ${ }^{1}$, Yannick Allanore ${ }^{1}$, Jérôme Avouacc. ${ }^{1}{ }^{1}$ Paris Descartes University, Cochin Hospital, Rheumatology, Paris, France; ${ }^{2}$ Paris Descartes University, Cochin Hospital, Gastroenterology, Paris, France; ${ }^{3}$ Paris Descartes University, Cochin Hospital, Pharmacy, Paris, France; ${ }^{4}$ Paris Descartes University, Cochin Hospital, Immunology, Paris, France; ${ }^{5}$ Paris Descartes University, Cochin Hospital, Internal Medicine, Paris, France

\section{Background:}

Objectives: To determine whether the successive switches from innovator infliximab to a first then a second biosimilar infliximab increase the risk of immunogenicity during a 3-year observation period.

Methods: This is a usual care study performed in Cochin Hospital, Paris, France. First switch from innovator infliximab to a first biosimilar infliximab occurred in October/December 2015 and the second switch from the first to the second biosimilar infliximab started in December 2017. The end of the observation period was December 2018. Immunogenicity was defined by the detection of positive antidrug antibodies (ADA $>10 \mathrm{ng} / \mathrm{mL}$ ), at least at two consecutive time points. The primary outcome of the study was the development of immunogenicity during the observation period. Secondary outcomes were i) the point prevalence of positive ADA at baseline, ii) the influence of the successive switches to biosimilars on the risk of immunogenicity and iii) the retention rate of biosimilar infliximab at the end of the observation period.

Results: Our prospective cohort consisted on 265 patients on maintenance therapy with innovator infliximab (135 axSpA, 64 with inflammatory bowel diseases, IBD, 31 with RA, 21 with PsA, 8 with uveitis and 6 with other chronic inflammatory diseases) who switched to biosimilar infliximab. Then, 140 patients switched to the second biosimilar infliximab, 26 remained treated with the first biosimilar, and innovator infliximab was re-established in 55 patients. 29 patients ( 15 females, 14 males) had positive ADA at baseline (point prevalence: $12.4 \%$ ), before the switch to biosimilar infliximab. Among these 29 patients, 15 had axSpA (11\%), 6 RA $(19 \%), 6$ IBD (9\%) and 2 PSa (10\%). Among the 236 patients with no ADA at baseline, 20 patients developed ADA during the observation period, corresponding to a rate of 3 for 100 patient years. The mean time to positive ADA detection was $21.2 \pm 13.7$ months. Kaplan Meyer curve showed no influence of the number of biosimilars infliximab received on immunogenicity (Figure 1A). Among the 20 patients with positive ADA, 4 were back to innovator infliximab at the time of ADA detection, 10 patients were exposed to the first biosimilar and 6 to the second The risk of treatment discontinuation was significantly higher in patients with positive ADA at baseline or during follow-up compared to patients without ADA (Figure 1B, Hazard Ratio 2.27, 95\% confidence interval 1.33-3.89). No predictive factor of immunogenicity was identified (including type of disease, age, sex, BMI or concomitant DMARD intake). The retention rate of biosimilar infliximab (Figure 1C) was $58 \%(154 / 265)$ at the end of observation period, including 131 patients treated with the second biosimilar and 23 who remained treated with the firs biosimilar.

Conclusion: In this usual care study with a 3-year observation period, the development of immunogenicity was low ( 3 for 100 patient years) and not favored by the switch to biosimilars infliximab. Thus, immunogenicity does not constitute a barrier to interchangeability between biosimilars infliximab in chronic inflammatory diseases. 


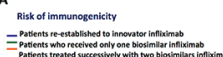

B
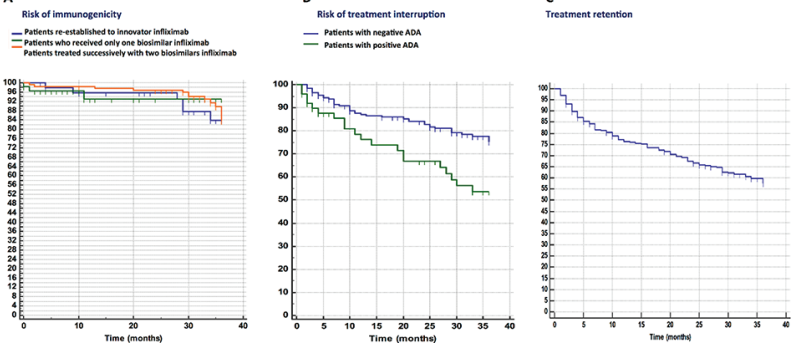

Figure 1. Kaplan Meyer Survival Analyses. A, risk of immunogenicity according to the number of biosimilars infliximab received; $B$, risk of treatment interruption according to the presence of anti-drug antibodies (ADA); and C, treatment retention within the observation period

Disclosure of Interests: Ambre Lauret: None declared, Anna Moltó: None declared, Vered Abitbol: None declared, Loriane Gutermann: None declared, Ornella Conort: None declared, Francois Chast: None declared, Claire Goulvestre: None declared, Claire Le Jeunne: None declared, Stanislas Chaussade: None declared, Christian Roux Grant/research support from: Alexion, Amgen, UCB, Frédéric Batteux: None declared, maxime dougados Grant/research support from: Eli Lilly and Company, Pfizer, AbbVie, and UCB Pharma, Consultant for: Eli Lilly and Company, Pfizer, AbbVie, and UCB Pharma, Yannick Allanore Grant/research support from: Inventiva, F Hoffman La-Roche, Sanofi, BMS, Pfizer, Consultant for: Actelion, Bayer, BMS, Boehringer, Roche, Sanofi, Jérôme Avouac Grant/research support from: research grant from Pfizer

DOI: 10.1136/annrheumdis-2019-eular.3702

\begin{tabular}{|l|l|}
\hline OP0228 & GSK3196165 AN INVESTIGATIONAL ANTI-GM-CSF \\
MONOCLONAL ANTIBODY, IMPROVES PATIENT \\
REPORTED OUTCOMES IN A PHASE IIB STUDY OF \\
PATIENTS WITH RHEUMATOID ARTHRITIS (RA)
\end{tabular}

Chris Buckley ${ }^{1}$, Jesus Simon Campos ${ }^{2}$, Vyacheslav Zhdan ${ }^{3}$, Brandon Becker ${ }^{4}$, Deven Chauhan ${ }^{5}$, Katherine Davy ${ }^{6}$, Carol Hawkes ${ }^{5}$, David Inman ${ }^{6}$, Mark Layton ${ }^{6}$, Jatin Patel ${ }^{5}$, Didier Saurigny ${ }^{6}$, Nina Mitchell ${ }^{7}$, Russell Williamson ${ }^{7}$, Paul Peter Tak ${ }^{7}$. ${ }^{1}$ University of Birmingham, Birmingham, United Kingdom; ${ }^{2}$ Köhler and Milstein Research, Mérida, Mexico; ${ }^{3}$ M.V. Sklifosovskyi Poltava Regional Clinical Hospital, Poltava, Ukraine; ${ }^{4}$ GlaxoSmithKline, Upper Providence, United States of America; ${ }^{5}$ GlaxoSmithKline, Uxbridge, United Kingdom; ${ }^{6}$ GlaxoSmithKline, Stevenage, United Kingdom; ${ }^{7}$ Formerly GlaxoSmithKline, Stevenage, United Kingdom

Background: GSK3196165 is a human mAb that inhibits GM-CSF, a key driver in a broad range of immune-mediated conditions (Hamilton, 2016). In trials of patients with RA, inhibition of GM-CSF signaling has resulted in clinical benefit. GM-CSF is not only a key mediator of inflammation, but emerging science suggests it is also an important regulator of pain.

Objectives: To evaluate the treatment effect of GSK3196165 on pain, fatigue, physical functioning, mental functioning and global assessment of disease, in patients with moderate-to-severely active RA.

Methods: 222 adult patients with active, moderate-severe RA (ACR 2010 criteria), $\geq 4$ each of swollen and tender joints, DAS28(CRP) $\geq 3.2$ and CRP $\geq 5.0 \mathrm{mg} /$ L, were randomized equally to placebo or GSK3196165 $22.5 \mathrm{mg}, 45 \mathrm{mg}, 90 \mathrm{mg}$, $135 \mathrm{mg}$ or $180 \mathrm{mg} \mathrm{SC}$ weekly for 5 injections, then every other week until Week 50. The Patient Reported Outcomes (PROs) measured throughout the study included, pain Visual Analogue Scale (VAS), Patient's Global Assessment of Arthritis (PtGA), Health Assessment Questionnaire - Disability Index (HAQ-DI), Brief Fatigue Inventory (BFI) Question 3, the Functional Assessment of Chronic IIIness Therapy - Fatigue (FACIT-F), and the 36-item short form health survey (SF36). The primary outcome was the proportion of patients who achieved remission (DAS28(CRP) <2.6) at Week 24 and the data has been previously reported (Buckley, 2018).

Results: 37 patients were randomised to each treatment group. The observed GSK3196165 pharmacokinetic exposures were lower than anticipated but despite this, there was a rapid and substantial improvement in RA symptoms in patients treated with GSK3196165 compared with placebo.

The table below summarizes the change from baseline data for the GSK3196165 $180 \mathrm{mg}$ dose and placebo at Week 12. An increase in the FACIT-F and SF-36 scores and a decrease in all other scores indicate an improvement in RA symptoms.

\begin{tabular}{|c|c|c|c|}
\hline $\begin{array}{l}\text { PRO endpoint at } \\
\text { Week } 12\end{array}$ & $\begin{array}{l}\text { Placebo } \\
(\mathrm{N}=37)\end{array}$ & $\begin{array}{c}\text { GSK3196165 180mg } \\
(\mathrm{N}=37)\end{array}$ & \\
\hline & \multicolumn{2}{|c|}{$\begin{array}{l}\text { Least squares mean change from } \\
\text { baseline (SE) }\end{array}$} & $\begin{array}{l}\text { Difference from placebo } \\
\quad(95 \% \mathrm{Cl}, \mathrm{p} \text { Value })\end{array}$ \\
\hline Pain VAS & $\begin{array}{l}-7.07 \\
(3.705)\end{array}$ & $-25.01(3.650)$ & $\begin{array}{c}-17.94(-28.18,-7.70 \\
p<0.001)\end{array}$ \\
\hline PtGA & $\begin{array}{c}-6.72 \\
(3.660)\end{array}$ & $-23.90(3.606)$ & $\begin{array}{c}-17.18(-27.27,-7.10 \\
p<0.001)\end{array}$ \\
\hline HAQ-DI & $\begin{array}{l}-0.26 \\
(0.091)\end{array}$ & $-0.50(0.090)$ & $\begin{array}{c}-0.24(-0.49,0.01 \\
p=0.059)\end{array}$ \\
\hline BFI Question 3 & $\begin{array}{c}-0.63 \\
(0.346)\end{array}$ & $-2.20(0.339)$ & $\begin{array}{c}-1.57(-2.53,-0.62 \\
p=0.001)\end{array}$ \\
\hline FACIT-F & $\begin{array}{c}3.37 \\
(1.291)\end{array}$ & $8.70(1.262)$ & $5.33(1.77,8.89, p=0.004)$ \\
\hline $\begin{array}{l}\text { SF-36 } \\
\text { Physical Component }\end{array}$ & $\begin{array}{c}3.42 \\
(1.203)\end{array}$ & $6.97(1.182)$ & $3.55(0.22,6.88, p=0.037)$ \\
\hline SF-36 & 3.54 & $6.79(1.521)$ & $3.25(-1.05,7.54, p=0.138$ \\
\hline Mental Component & $(1.558)$ & & \\
\hline
\end{tabular}

Conclusion: The results of this Phase llb study showed that GSK3196165 substantially improved the scores of a range of PRO measures among RA patients. In particular, there was a highly significant improvement in pain; a key symptom of RA. These effects were observed despite achieving much lower drug exposure than predicted. Further studies are required to confirm the additional patient relevant benefits that are expected to arise from increased exposure to GSK3196165.

\section{REFERENCES:}

[1] Hamilton JA, Cook AD, Tak PP. Anti-colony-stimulating factor therapies for inflammatory and autoimmune diseases. Nat Rev Drug Discov 2016; 16:53-70

[2] Buckley C, et al. A Phase Ilb Dose-Ranging Study of Anti-GM-CSF with Methotrexate Treatment in Patients with Rheumatoid Arthritis (RA) and an Inadequate Response to Methotrexate. Arthritis Rheumatol. 2018;70 (Suppl 10): abs 1938

Disclosure of Interests: Chris Buckley Consultant for: GlaxoSmithKline, Jesus Simon Campos: None declared, Vyacheslav Zhdan: None declared, Brandon Becker Shareholder of: GlaxoSmithKline, Employee of: GlaxoSmithKline, Deven Chauhan Shareholder of: GlaxoSmithKline, Employee of: GlaxoSmithKline, Katherine Davy Shareholder of: GlaxoSmithKline, Employee of: GlaxoSmithKline, Carol Hawkes Shareholder of: I own shares in GlaxoSmithKline, Employee of: I am currently an employee of GlaxoSmithKline, David Inman Shareholder of: GlaxoSmithKline, Employee of: GlaxoSmithKline, Mark Layton Shareholder of: GlaxoSmithKline, Employee of: GlaxoSmithKline, Jatin Patel Shareholder of: GlaxoSmithKline, Employee of: GlaxoSmithKline, Didier Saurigny Shareholder of: GlaxoSmithKline, Employee of: GlaxoSmithKline, Nina Mitchell Shareholder of: GlaxoSmithKline, Employee of: Former GlaxoSmithKline employee, Russell Williamson Shareholder of: GlaxoSmithKline, Employee of: Former GlaxoSmithKline employee, Paul Peter Tak Shareholder of: GlaxoSmithKline, Employee of: Former GlaxoSmithKline employee

DOI: 10.1136/annrheumdis-2019-eular.6035

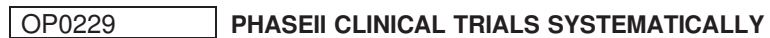 OVERESTIMATE TREATMENT EFFECTS OF SUBSEQUENT PHASE III TRIALS IN RHEUMATOID ARTHRITIS}

Andreas Kerschbaumer ${ }^{1}$, Harald Herkner ${ }^{2}$, Josef S. Smolen ${ }^{1}$, Daniel Aletaha ${ }^{1}$. ${ }^{1}$ Medical University of Vienna, Department of Medicine III, Division of Rheumatology, Vienna, Austria; ${ }^{2}$ Medical University of Vienna, Department of Emergency Medicine, Vienna, Austria

Background: Phase 3 (P3) clinical trials are the mainstay of drug development in all areas of medicine, including rheumatology, allowing to determine safety and efficacy of new drugs on their way to approval. Historically, efficacy results of P3 trials have often been disappointing with respect to the expectations set by phase 2 (P2) trials. It is unclear whether these observations are reflection of a true bias or merely a play of chance.

Objectives: To systematically compare efficacy results of $P 2$ versus $P 3$ trials in RA and investigate potential determinants of efficacy differences.

Methods: We performed a systematic review of disease modifying anti-rheumatic drugs (DMARDs) tested in P2 trials in rheumatoid arthritis (RA) over the last 20 years for which also P3 trials exist. We searched Medline, EMBASE, and the 